\title{
Prevalence and Factors Associated with Under Nutrition Among Newly Enrolled HIV Infected Adults Attending Ampath Ambulatory Clinic in Eldoret, Kenya
}

\author{
Peris Kebenei ${ }^{1}$, Robert Too $^{2}$, Taratisio Ndwiga $^{3}$ \\ ${ }^{1}$ Department of Nutrition, Moi Teaching and Referral Hospital, Eldoret, Kenya \\ ${ }^{2}$ Department of Epidemiology and Nutrition, School of Public Health, Moi University, Eldoret, Kenya \\ ${ }^{3}$ Department of Environmental Health, School of Public Health, Moi University, Eldoret, Kenya
}

Email address:

pkebenei@gmail.com (P. Kebenei), tookip_2000@yahoo.com (R. Too), taratisiondwiga@yahoo.com (T. Ndwiga)

\section{To cite this article:}

Peris Kebenei, Robert Too, Taratisio Ndwiga. Prevalence and Factors Associated with Under Nutrition Among Newly Enrolled HIV Infected Adults Attending Ampath Ambulatory Clinic in Eldoret, Kenya. Science Journal of Public Health. Vol. 6, No. 1, 2018, pp. 26-34. doi: 10.11648/j.sjph.20180601.15

Received: March 3, 2016; Accepted: December 4, 2017; Published: January 17, 2018

\begin{abstract}
Background: Nutrition is the main foundation for health and development of the human being. HIV infection increases nutrient requirements and at the same time impairs nutrient intake and absorption. Poor nutrition increases the risk of opportunistic infections, further increasing energy and nutrient needs, thus accelerating the progression of HIV to AIDS. Study Population: Newly enrolled HIV- infected adult patients. Objectives: To investigate the prevalence of under nutrition among newly enrolled HIV-infected adults attending the Academic Model for Providing Access to Healthcare clinic (AMPATH). Methodology: A cross-sectional survey was carried out on 288 consecutively enrolled subjects. The prevalence of under nutrition was determined based on the World Health Organization recommended BMI cut- off points. The contents of 24-hour recalls were entered into a nutrient calculator to determine the nutrient content and compared to the Recommended Dietary Allowance in order to determine adequacy of food. Results: Of the 288 respondents in the study, 153 (54.4\%) were female. For males and females the mean $\pm(\mathrm{SD})$ daily energy and protein intakes were $1856 \pm(536.8) \mathrm{Kcal} /$ day, $1680 \pm(517.3) \mathrm{kcal} / \mathrm{day}$, $62.4 \pm$ (20.7) g/day and 53.1 (17) g/day respectively. Folate, zinc, iron and vitamin A were significantly below the Recommended Dietary Allowances (RDA). Adjusting for energy and protein intake, those with adequate Folate intake had $88.9 \%$ lower chances of being-nourished $(\mathrm{OR}=.111,95 \% \mathrm{CI} 0.013,0.973)$. Conclusion: Prevalence of under nutrition in the study population shows that $31.6 \%$ of subjects had inadequate Folate and Zinc intakes. Folate intake was a significant predictor of under-nutrition. It was recommended that patient health education on the need to consume foods rich in Folate and Zinc should be intensified in all the ambulatory clinics.
\end{abstract}

Keywords: Under Nutrition, House Hold Food Security, House Hold Dietary Diversity, HIV and AIDS

\section{Introduction}

The first case of Acquired Immune Deficiency Syndrome (AIDS) was reported in the United States of America in 1981 and in Kenya in 1984. AIDS is caused by the Human Immunodeficiency Virus (HIV), which is transmitted through sexual contact, infected blood, blood products or transplanted organs or tissues, and from an infected mother to a child. Almost three decades since the first AIDS case was discovered in Kenya, HIV and AIDS still remains a huge problem affecting social and economic development [1]. An estimated 1.4 million adults aged 15-64 years are infected with HIV and AIDS, with about one million rural and 400,000 urban residents infected [2]. The growing incidence of HIV and AIDS is also known to indirectly increase levels of under nutrition through its effects on food production. Under nutrition among People Living with HIV and AIDS (PLWHAs) manifests itself most commonly as weight loss in adults and children, and faltered linear growth (stunting) in children, as a result of deficiency in specific macro or 
micronutrients. Weight loss among PLWHA occurs due to reduced food intake (starvation), malabsorption, and sudden increase in energy expenditure, problems with energy utilization, or a combination of both [3]. The nutritional needs of PLWHA are influenced by several factors including age, physiological changes, level of physical activity, clinical state of health, metabolic rate and viral load count. To maintain good nutrition, an adequate intake of energy-giving foods, proteins, vitamins and minerals, fibre and water are vital. The fundamental concerns are to maintain a balance of foods from each food group and to consume a variety within each food group daily [3]. At the social level, food insecurity is a major cause of vulnerability to HIV, hence the need to invest in nutrition in order to break the vicious cycle between food insecurity and HIV vulnerability Therefore we investigate the prevalence and associated factors to under nutrition among newly enrolled HIV adults attending the AMPATH clinic.

PROBLEM STATEMENT: The number of people living with HIV in sub-Saharan Africa in 2008 was 2.4 million [4]; accounting for $67 \%$ of HIV infections worldwide; with $68 \%$ of new infections among adults. The region accounted for $72 \%$ of the world's AIDS- related deaths; in a year when Kenya had a prevalence of $7.8 \%$. In 2007, an estimated 1.42 million people in Kenya are infected with HIV, the virus that causes AIDS [5]. In 2012, national HIV prevalence was estimated to be 5.6\% among Kenyans aged 15-64 years, significantly lower than the HIV prevalence estimate in 2007. The significant decline in HIV prevalence was observed among both women and men. Still, women aged 15-64 years had higher HIV prevalence rates $(6.9 \%)$ than men $(4.4 \%)$ aged 15-64 years, and young women aged 20-24 years were at least three times more likely to be infected (4.6\%) than young men of the same age group (1.3\%). HIV prevalence in older adults aged 50-54 years remained high, at $8.4 \%$, but was lower among those aged 55-59 years (4.4\%) and aged 60-64 years $(4.0 \%)$ [12].

Nutrition and HIV are linked. Undernourished people have compromised immune systems, making them more vulnerable to HIV infection. HIV infection, in turn, makes it harder for people to absorb nutrients from food because of frequent diarrhea and other gastrointestinal anomalies. It also disrupts the absorption of fats and fat-soluble vitamins, exacerbating nutrient deficiencies. The virus also raises the energy spent resting, meaning that infected people need more protein than usual. There are social as well as clinical implications. Hunger can force people into risky behavior, such as selling sex for food or money, heightening their chance of HIV infection.

Any immune impairment as a result of HIV and AIDS can contribute to under nutrition, which leads to immune impairment, worsening the effects of HIV and contributing to a more rapid progression of the disease. In a sense, under nutrition both contribute to and is a result of HIV disease progression [7]. When an under nourished person acquires $\mathrm{HIV}$, he/she progresses faster to AIDS because the body is already weak and cannot fight co-infections. A well- nourished person has a stronger immune system for coping with HIV and fighting illness. HIV infection affects nutrition through increases in resting energy expenditure, reductions in food intake, nutrient malabsorption and loss, and complex metabolic alterations that culminate in weight loss and wasting common in AIDS. The effect of HIV on nutrition begins early in the course of the disease, even before an individual may be aware that he/she is infected with the virus. AIDS- wasting syndrome is defined as a $10 \%$ weight loss of baseline body weight plus either chronic diarrhea (two loose stools per day for more than 30 days) or chronic weakness and documented fever for 30 days or more, intermittent or constant, in the absence of a concurrent illness or a condition other than HIV infection: wasting is characterized by a loss of lean tissues, responsible for most of the body's metabolic functions including processing medications. The body starts to lose its major functions as damage to the immune system and weight loss progress [7]. Symptoms and illnesses commonly caused by HIV infection have nutritional consequences that can lead to malnutrition. These include Anorexia (which leads to general weight loss and is common when individuals are depressed or living in socially and emotionally unfavorable environments) Diarrhea (a person has several loose bowel movements in a day), Fever (people with acute or chronic fever may have chills, sweat excessively, have muscle and joint aches, or be fatigued - this causes increased energy requirements) and anemia (this is a low level of hemoglobin in the blood - HIVinfected persons who are anemic generally progress faster to AIDS than those who are not). As HIV infection progresses, it causes a catabolic state and increased susceptibility to infection which are compounded by lack of caloric and other nutrient intake, leading to progressive worsening of under nutrition. Under nutrition therefore both contributes to and is a result of HIV disease progression [13]. A well nourished person has a stronger immune system for coping with HIV and fighting illness. It is thus apparent that nutrition intervention at enrollment may have a positive impact on HIV outcomes.

JUSTIFICATION: About 1.02 billion People are estimated to suffer from under nutrition globally [8] with $99 \%$ of these living in developing countries. Poor nutrition leads to an increase in opportunistic infections; increasing energy ad nutrient needs thus accelerating the progression of HIV to AIDS. It also leads to reduced food production; hence declining income and ultimately a negative impact on the economy. On the other hand, good nutrition leads to an improved immune system, boosts energy and helps recovery from opportunistic infections. Assessment of nutritional status and nutritional risks through the determination of the HIV patients' dietary intake, global anthropometric and body composition measurements as well as macro and micronutrient status are important for early detection of poor nutrition. The nutritional needs of HIV-infected persons depend on the disease progression, with the various phases of the infection being marked by an increase in metabolism, increased energy requirements and energy depletion [7;9]. 


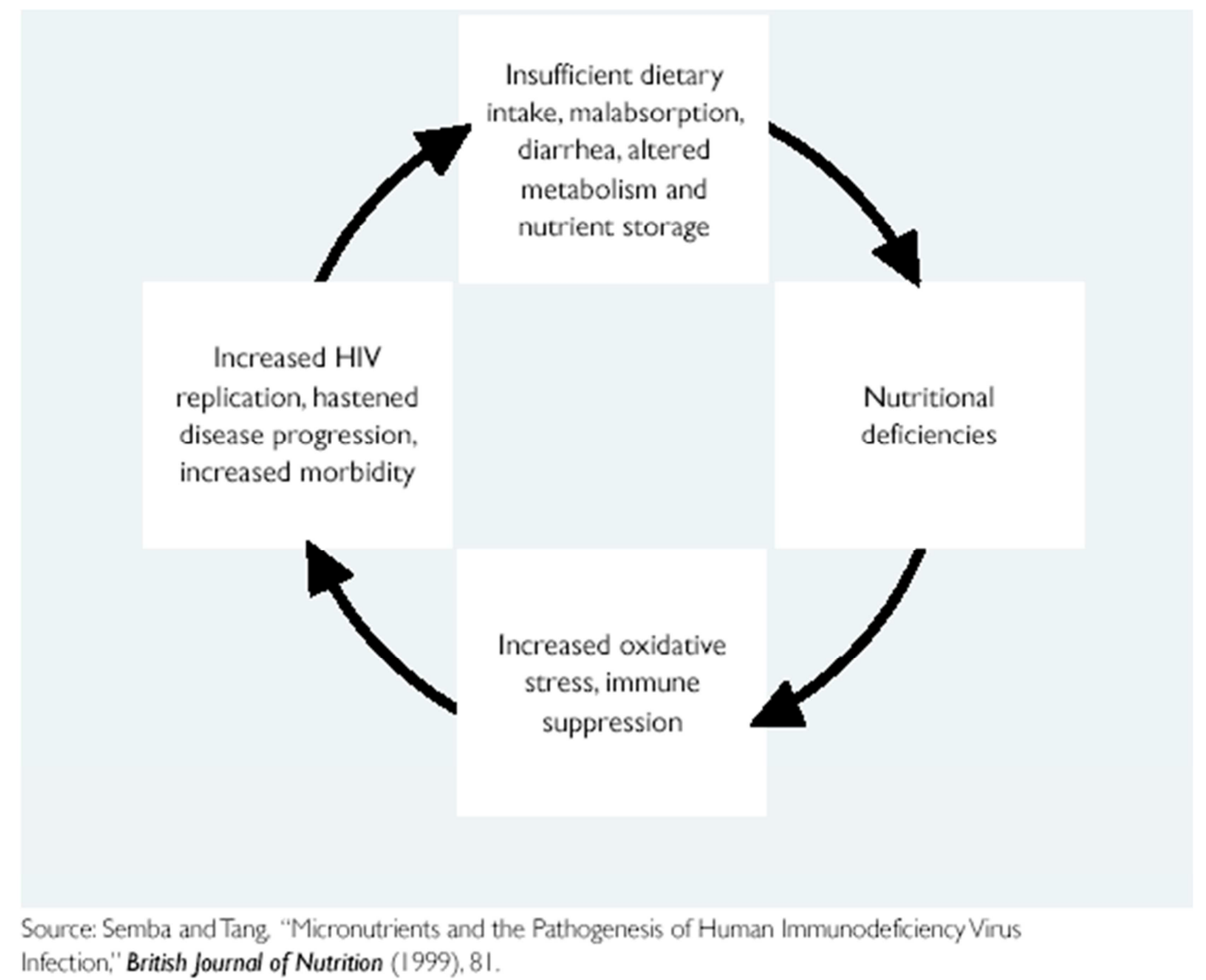

Figure 1. The vicious cycle of malnutrition and HIV.

Food and nutrition interventions are critical components of a comprehensive response to the HIV pandemic. HIV compromises the nutritional status of infected individuals; and under nutrition can in turn worsen the effects of the disease. Nutrition interventions can help break this cycle (Figure 1) by helping PLWAs manage symptoms, reduce susceptibility to opportunistic infections, improve the nutritional status, promote response to medical treatment and improve overall quality of life. Investing in nutrition in HIV and AIDS will have both short and long term benefits of economic and social significance, reduced health care costs and productivity. However, studies on under nutrition among newly enrolled HIV infected patients have not been done in this region, hence this study sought to find out nutritional status of newly enrolled patients and associated factors in order to inform intervention programs.

RESEARCH QUESTION: What is the level of under nutrition among PLWHAs and what factors, if any, are associated with under nutrition among newly enrolled adult HIV-infected patients attending the AMPATH HIV ambulatory clinic?

\section{Materials and Methods}

\subsection{Study Area and Population}

The study was conducted at the AMPATH Centre, Moi
Teaching and Referral Hospital (MTRH) Eldoret, Kenya. Eldoret is located $320 \mathrm{~km}$ west of Nairobi; with an estimated population of 400,000 people. AMPATH is a working model of urban and rural HIV preventive and treatment services in the public sector; caring for more than 100,000 HIV-infected adults and children. MTRH is the second National referral hospital in Kenya, and hosts the Medical school of Moi University. The study population consisted of newly enrolled HIV- infected adult patients.

\subsection{Study Design and Sampling}

A descriptive cross-sectional study was carried out on 288 consecutively enrolled subjects.

\subsection{Data Collection}

Data was collected using interviewer administered questionnaires which contained both open and close ended questions. This was used to determine socio demographic factors of the respondents that affected their nutritional status. A 24 hour recall was also completed at that time and was used to determine adequacy of the micro and macro nutrients intake and diet diversity at individual level. Anthropometric measurements of weight, height and arm circumference were recorded. Measurements of fat located just underneath the skin (subcutaneous fat) were done at the triceps using the skin fold thickness callipers. 
A complete list of all foods and beverages consumed over the previous 24-hour period was obtained and adequacy of nutrient intake calculated. The derivatives from anthropometric measurements included Body Mass Index, Mid Upper Arm Muscle Area and Body Fat percentage. BMI was computed following the standard formula: BMI= Weight $(\mathrm{kg}) /$ height $\left(\mathrm{m}^{2}\right)$.

The following World Health Organization recommended BMI cut- off points were utilized to determine the nutritional status of the subjects:

$\begin{array}{ll}\text { Nutritional status } & \text { BMI }\left(\mathrm{kg} / \mathrm{m}^{2}\right) \\ \text { Under nutrition } & <18.5 \\ \text { Normal } & 18.5-24.9 \\ \text { Overweight } & \geq 25.0\end{array}$

\subsection{Data Analysis}

The prevalence of under nutrition was determined based on anthropometric measurements. Household food security was assessed using the Household Dietary Diversity Score (HDDS) and Household Food Insecurity Access Scale (HFIAS). Adequacy of nutrient intake was assessed using the $24 \mathrm{hr}$ recall. All the analysis was done using SPSS version 12.0 and nutrient calculator. Mean nutrient intake was compared with RDA. Frequency tables, means, chi-square test of association and analysis of variance (ANOVA) were employed. Significance was assumed for $\mathrm{p} \leq 0.05$.

\section{Results}

\subsection{Socio- Demographic Characteristics}

Table 1. The socio-demographic characteristics of the 288 respondents.

\begin{tabular}{ll}
\hline Characteristics & N (\%) \\
\hline Gender & $128(44.4)$ \\
Male & $160(55.6)$ \\
Female & \\
Marital status & $136(47.2)$ \\
Married & $121(42)$ \\
Single & $20(6.9)$ \\
Widowed & $11(3.8)$ \\
Divorced & \\
Education & $40(13.9)$ \\
None & $127(44.1)$ \\
Primary & $106(36.8)$ \\
Secondary & $15(5.2)$ \\
Tertiary & \\
Income (Shs) & $241(83.7)$ \\
$1000-4999$ & $35(12.2)$ \\
$5000-9999$ & $3(1.0)$ \\
$10000-14999$ & $9(3.1)$ \\
\hline
\end{tabular}

WHO stages of the newly diagnosed HIV infected adults at AMPATH Centre

Majority of the respondents $164(56.9 \%)$ had more than 200 CD4 cell counts/ $\mu 1$. Minority $41(14.2 \%)$ had between 0 50 CD4 cell counts. Among the respondents studied, majority $118(41 \%)$ were in WHO stage 1.

Minority 32(11.1\%) were in WHO stage 4 as in Figure 2.

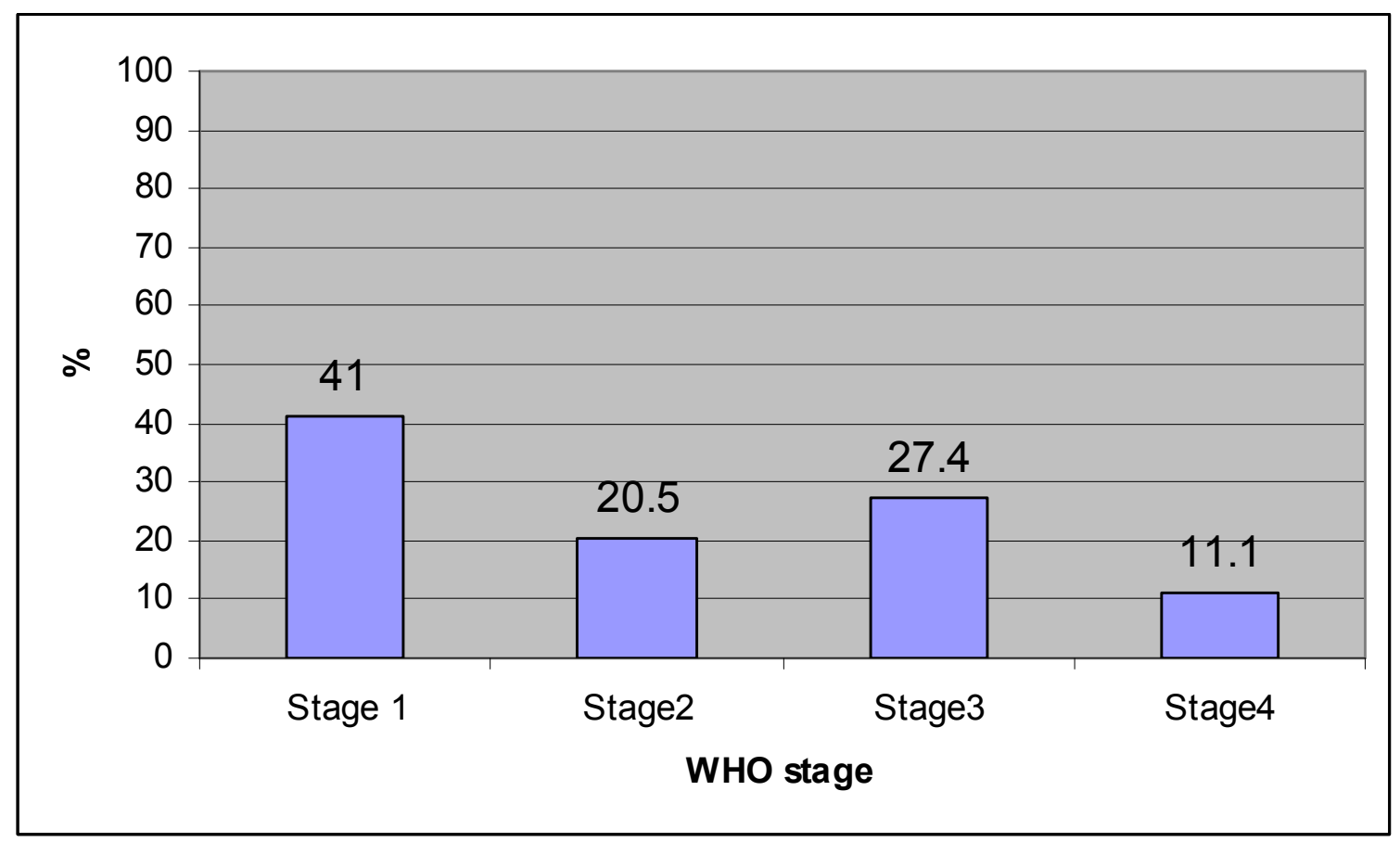

Figure 2. WHO stages of the newly diagnosed HIV infected adults at AMPATH Centre.

\subsection{Prevalence of Under Nutrition}

In the study, 91(31.6\%) were underweight while 34(11.8\%) were overweight as indicated in Figure 3 . The prevalence of under nutrition based on BMI is $31.6 \%$ 


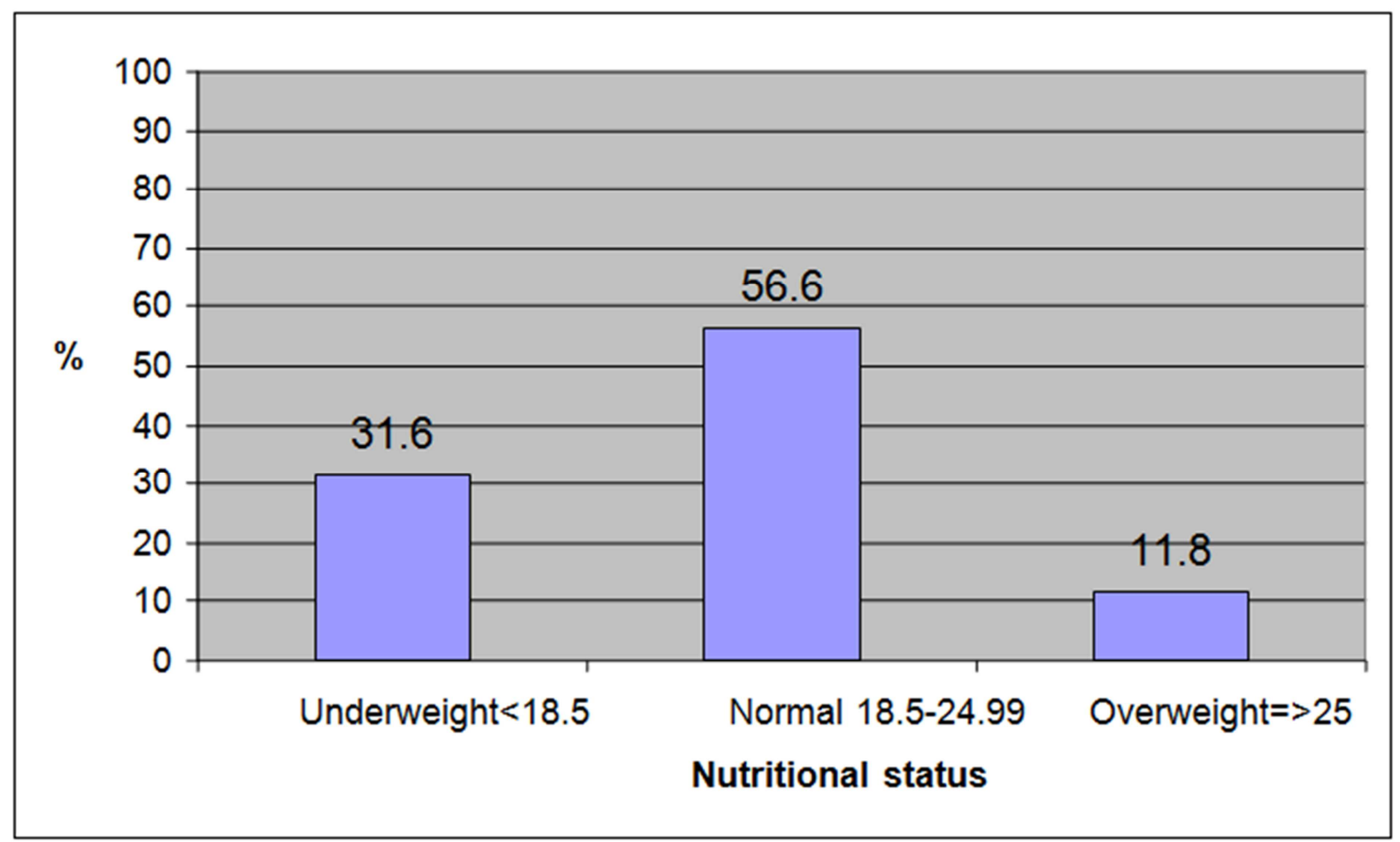

Figure 3. Nutritional status based on BMI.

\subsection{Relationship Between CD4 Cell Count and Body Mass Index}

A correlation between Body Mass Index and the CD4 count of the respondents yielded a Pearson's value, $\mathrm{r}=0.111$, and an associated probability, $\mathrm{p}=0.06$. A bigger percentage of female respondents than male were undernourished. Among the 128 male patients studied, 2(1.6\%) had unhealthy hipratio, while $120(75 \%)$ of the women had unhealthy hip ratio
(Cut-offs Male $\leq 1$ and Female $\leq 0.8$ ).

\subsection{Factors Associated with Under Nutrition}

The Mean daily intake of energy was $1856.5 \pm 536$ $\mathrm{kcal} /$ day and $1658 \pm 513 \mathrm{Kcal} /$ day for male and female respectively. Macronutrient intake was generally low compared to the RDA with a mean protein intake of $62.4 \pm$ 20.1.g/day for males and $53.1 \pm 17.6 \mathrm{~g} /$ day for females.

Table 2. Mean daily macronutrient intake in relation to $R D A$.

\begin{tabular}{|c|c|c|c|c|c|c|c|c|c|}
\hline Nutrient & Age group & \multicolumn{2}{|c|}{ Mean intake } & \multicolumn{2}{|l|}{ RDA } & \multicolumn{2}{|c|}{$\%$ RDA } & \multicolumn{2}{|c|}{ P-value } \\
\hline \multirow{4}{*}{$\begin{array}{l}\text { Energy (Kcal) } \\
\text { Protein(g) }\end{array}$} & & $\mathrm{M}$ & $\mathrm{F}$ & $\mathrm{M}$ & $\mathrm{F}$ & $\mathrm{M}$ & $\mathrm{F}$ & $\mathrm{M}$ & $\mathrm{F}$ \\
\hline & $18-29$ & 1984 & 1634 & 2550 & 2000 & 77.8 & 81.7 & $<0.001$ & $<0.001$ \\
\hline & $30-59$ & 1817 & 1681 & 2500 & 2000 & 72.7 & 84.1 & $<0.001$ & $<0.001$ \\
\hline & $30-59$ & 61 & 53 & 68 & 58 & 89.7 & 91.4 & 0.001 & 0.003 \\
\hline
\end{tabular}

Factors associated with nutrient intake.

Table 3. Macro nutrients intake by level of education stratified by gender

\begin{tabular}{|c|c|c|c|c|c|c|c|}
\hline \multicolumn{8}{|c|}{ ANOVA of Macro nutrients intake by level of education stratified by gender } \\
\hline Gender of & respondent & & Sum of Squares & Df & Mean Square & $\mathbf{F}$ & Sig. \\
\hline \multirow{6}{*}{ MALE } & \multirow{3}{*}{ Client daily Energy intake (kcal) } & Between Groups & 505964.114 & 3 & 168654.705 & .580 & .630 \\
\hline & & Within Groups & 3.609E7 & 124 & 291022.491 & & \\
\hline & & Total & 3.659E7 & 127 & & & \\
\hline & \multirow{3}{*}{ Client daily Protein intake } & Between Groups & 4823.083 & 3 & 1607.694 & 4.035 & .009 \\
\hline & & Within Groups & 49400.611 & 124 & 398.392 & & \\
\hline & & Total & 54223.694 & 127 & & & \\
\hline \multirow{6}{*}{ FEMALE } & \multirow{3}{*}{ Client daily Energy intake (kcal) } & Between Groups & 574449.246 & 3 & 191483.082 & .707 & .549 \\
\hline & & Within Groups & $4.225 \mathrm{E} 7$ & 156 & 270815.013 & & \\
\hline & & Total & $4.282 \mathrm{E} 7$ & 159 & & & \\
\hline & \multirow{3}{*}{ Client daily Protein intake } & Between Groups & 366.266 & 3 & 122.089 & .412 & .745 \\
\hline & & Within Groups & 46213.754 & 156 & 296.242 & & \\
\hline & & Total & 46580.020 & 159 & & & \\
\hline
\end{tabular}


Table 4. Nutrient intake by marital status stratified by gender.

\begin{tabular}{|c|c|c|c|c|c|c|c|}
\hline \multicolumn{8}{|c|}{ ANOVA of nutrient intake by marital status stratified by gender } \\
\hline Gender of & espondent & & SS & Df & MSS & $\mathbf{F}$ & Sig. \\
\hline \multirow{11}{*}{ MALE } & \multirow{3}{*}{ Client daily Protein intake } & Between Groups & 11078.069 & 3 & 3692.690 & 10.613 & .000 \\
\hline & & Within Groups & 43145.626 & 124 & 347.949 & & \\
\hline & & Total & 54223.694 & 127 & & & \\
\hline & \multirow{3}{*}{ Client daily Zinc intake } & Between Groups & 27.273 & 3 & 9.091 & 3.634 & .015 \\
\hline & & Within Groups & 310.214 & 124 & 2.502 & & \\
\hline & & Total & 337.486 & 127 & & & \\
\hline & \multirow{2}{*}{$\begin{array}{l}\text { Client daily Energy intake } \\
\text { in (kcal) }\end{array}$} & Within Groups & $3.447 \mathrm{E} 7$ & 124 & 278002.835 & & \\
\hline & & Total & $3.659 \mathrm{E} 7$ & 127 & & \multirow{4}{*}{.912} & \\
\hline & \multirow{3}{*}{$\begin{array}{l}\text { Client daily vitamin A } \\
\text { intake }\end{array}$} & Between Groups & 307283.862 & 3 & 102427.954 & & \multirow[t]{3}{*}{.437} \\
\hline & & Within Groups & $1.392 \mathrm{E} 7$ & 124 & 112265.023 & & \\
\hline & & Total & $1.423 \mathrm{E} 7$ & 127 & & & \\
\hline \multirow{11}{*}{ FEMALE } & \multirow{2}{*}{$\begin{array}{l}\text { Client daily } \\
\text { protein intake }\end{array}$} & Between Groups & 7787.771 & 3 & 2595.924 & \multirow[t]{2}{*}{10.439} & \multirow[t]{2}{*}{.000} \\
\hline & & Within Groups & 38792.248 & 156 & 248.668 & & \\
\hline & \multirow{3}{*}{ Client daily zinc intake } & Between Groups & 47.974 & 3 & 15.991 & \multirow[t]{3}{*}{9.149} & \multirow[t]{3}{*}{.000} \\
\hline & & Within Groups & 272.675 & 156 & 1.748 & & \\
\hline & & Total & 320.649 & 159 & & & \\
\hline & \multirow{3}{*}{$\begin{array}{l}\text { Client daily energy intake } \\
\text { in (kcal) }\end{array}$} & Between Groups & 8128667.820 & 3 & 2709555.940 & \multirow[t]{3}{*}{12.184} & \multirow[t]{3}{*}{.000} \\
\hline & & Within Groups & $3.469 \mathrm{E} 7$ & 156 & 222390.535 & & \\
\hline & & Total & $4.282 \mathrm{E} 7$ & 159 & & & \\
\hline & \multirow[t]{3}{*}{$\begin{array}{l}\text { Client daily vitamin A } \\
\text { intake }\end{array}$} & Between Groups & 1239592.184 & 3 & 413197.395 & \multirow[t]{3}{*}{4.620} & \multirow[t]{3}{*}{.004} \\
\hline & & Within Groups & $1.395 \mathrm{E} 7$ & 156 & 89430.429 & & \\
\hline & & Total & $1.519 \mathrm{E} 7$ & 159 & & & \\
\hline
\end{tabular}

\subsection{Household Food Insecurity Scale (HFIAS)}

set of questions proposed by FANTA [13] household food

In order to ascertain the number of households that were insecurity access scale for measurement of food access indicator guide version 3.0 was used. experiencing household food insecurity-related conditions, a

Table 5. Household Perceptions on Ability to Access Food in the Previous one Month.

\begin{tabular}{|c|c|c|c|c|}
\hline \multirow{2}{*}{ Indicator } & \multicolumn{4}{|c|}{ Frequency of Occurrence $(\%)$} \\
\hline & Never & Rarely & Sometimes & Often \\
\hline Worried about insufficient food(N=288) & $179(62.2)$ & $9(3.1)$ & $46(16)$ & $54(18.8)$ \\
\hline Not able to eat preferred foods $(\mathrm{N}=288)$ & $179(62.2)$ & $17(5.9)$ & $26(9)$ & $66(22.9)$ \\
\hline Ate a limited variety of foods $(\mathrm{N}=288)$ & $179(62.2)$ & $9(3.1)$ & $26(9)$ & $74(25.7)$ \\
\hline Ate none preferred foods $(\mathrm{N}=288)$ & $179(62.2)$ & $9(3.1)$ & $26(9)$ & $74(25.7)$ \\
\hline Ate smaller meals $(\mathrm{N}=288)$ & $179(62.2)$ & $17(5.9)$ & $33(11.5)$ & $59(20.5)$ \\
\hline Ate fewer meals $(\mathrm{N}=288)$ & $88(30.6)$ & $52(18)$ & $48(16.7)$ & $100(34.7)$ \\
\hline Ate no food at all $(\mathrm{N}=288)$ & $126(43.8)$ & $47(16.3)$ & $34(11.8)$ & $81(28.1)$ \\
\hline Slept hungry $(\mathrm{N}=288)$ & $200(69.4)$ & $27(9.4)$ & $22(7.6)$ & $39(13.5)$ \\
\hline Went a whole day without food $(\mathrm{N}=288)$ & $206(71.5)$ & $27(9.3)$ & $36(12.5)$ & 19 (6.6) \\
\hline
\end{tabular}

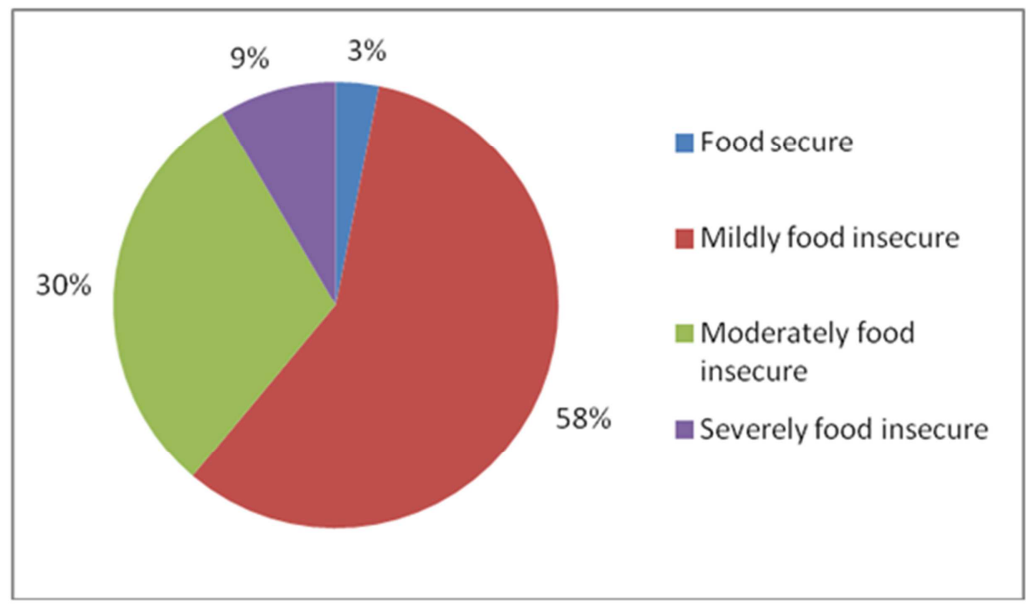

Figure 4. Prevalence of household food insecurity. 


\subsection{Prevalence of Household Food Insecurity}

To be able to determine the household food insecurity prevalence, households were categorized into four levels of household food insecurity. These included food secure, mild, moderately and severe food insecure (Figure 4).

\subsection{Household Dietary Diversity Score (HDDS)}

In order to ascertain the number of households that were experiencing household food diversity related conditions, a total of 12 food groups were tabulated ranging from A- L [10], with either 0 (No) or 1(Yes) and each household was asked about the different food groups consumed. An increase in the average number of different food groups consumed provided a quantifiable measure of improved household food access. In general, any increase in household dietary diversity reflects an improvement in the household's diet.

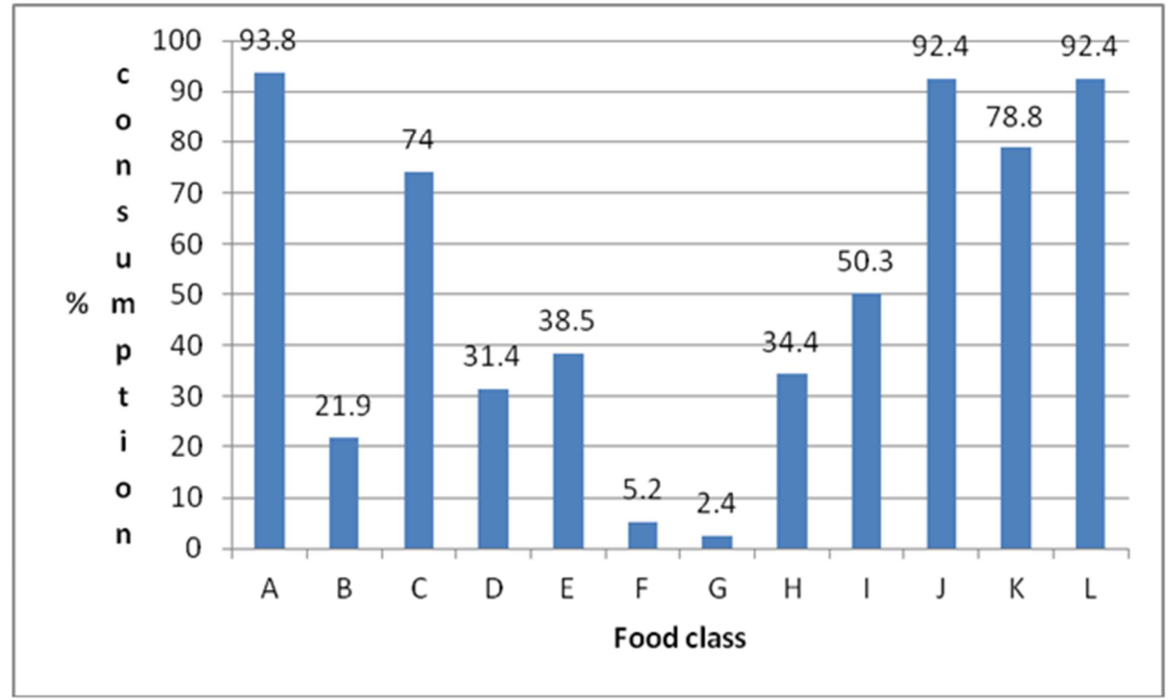

Figure 5. Types of food consumed.

Using the cut off point as 5 after summing up the responses on the different types of food consumed in the households, $56(20 \%)$ of the households did not consume diversified diets (Figure 5).

\subsection{Association Between Disease Status indicators and Under Nutrition}

Table 6. Disease status indicators and under nutrition.

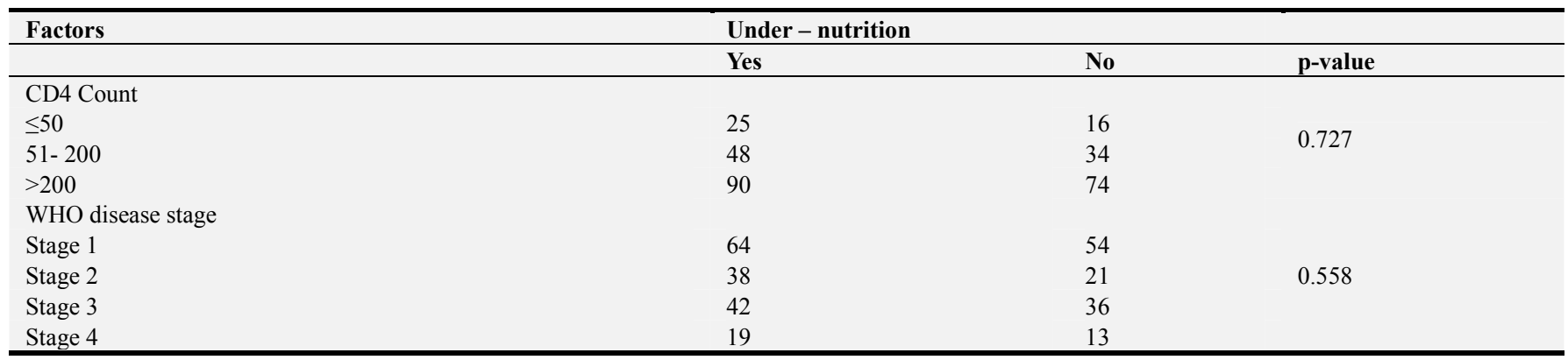

\subsection{Association Between Under Nutrition and Nutrient Intake}

Table 7. Under nutrition and nutrient intake.

\begin{tabular}{|c|c|c|c|c|}
\hline \multirow{2}{*}{ Nutrient inadequacy } & \multicolumn{2}{|c|}{ Under-Nutrition } & \multirow{2}{*}{$\chi^{2}-$ Value } & \multirow{2}{*}{ p-value } \\
\hline & Yes & No & & \\
\hline \multicolumn{5}{|l|}{ Energy } \\
\hline Yes & 98 & 145 & 5.344 & 0.021 \\
\hline No & 26 & 18 & & \\
\hline \multicolumn{5}{|l|}{ Protein } \\
\hline Yes & 74 & 120 & 6.250 & 0.012 \\
\hline No & 50 & 43 & & \\
\hline Yes & 78 & 101 & 0.027 & 0.871 \\
\hline
\end{tabular}




\begin{tabular}{lllll}
\hline \multirow{2}{*}{ Nutrient inadequacy } & Under-Nutrition & No & $\chi^{2}$-Value & p-value \\
\cline { 2 - 3 } No & Yes & 62 & & 0.078 \\
Vitamin C & 46 & & 0.781 \\
Yes & 71 & 96 & \\
No & 53 & 67 & 6.58 & 0.010 \\
Folate & 117 & 162 & \\
Yes & 7 & 1 & & 0.223 \\
No & & & \\
Iron & 81 & 94 & \\
Yes & 42 & 66 & & \\
No & & & \\
Zinc & 123 & 159 & 2.302 & 0.129 \\
Yes & 0 & 3 & \\
No & & & \\
\hline
\end{tabular}

Table 8. Multiple binary logistic regression.

\begin{tabular}{|c|c|c|c|c|c|c|c|c|}
\hline \multirow{2}{*}{ Nutrient inadequacy } & \multirow{2}{*}{ B } & \multirow{2}{*}{ S.E } & \multirow{2}{*}{ Wald } & \multirow{2}{*}{ Df } & \multirow{2}{*}{ Sig. } & \multirow{2}{*}{ OR } & \multicolumn{2}{|c|}{ 95.0\% C.I. for OR } \\
\hline & & & & & & & Lower & Upper \\
\hline Energy & -.133 & .422 & .100 & 1 & .752 & .875 & .383 & 2.001 \\
\hline Protein & -.581 & .313 & 3.3438 & 1 & .064 & .560 & .303 & 1.034 \\
\hline Folate & -2.200 & 1.108 & 3.940 & 1 & .047 & .111 & .013 & .993 \\
\hline Constant & 2.377 & 1.090 & 4.753 & 1 & .029 & 10.777 & & \\
\hline
\end{tabular}

\section{Discussion}

The findings on the prevalence of under nutrition from this study were high (31.6\%) compared to two studies [4] and [5]. Findings are however lower than those of another study [7]. These differences may have resulted due to the fact that this study was carried out in a specific locality within Kenya with a smaller population as opposed to the 11 countries sampled in the other studies. There was no statistically significant trend of adults with chronic energy deficit living in food insecure households (as measured by HFIAS and HDDS). One possible reason for the lack of association between BMI and HDDS is that only the diet of the previous day is considered while an adult's body weight is reflective of a longer time period. Energy and Protein intake in the study population were below the Recommended Daily Allowances for adults and strongly associated with under nutrition. Macro and micronutrient intake were below the Expected Average Requirements. These findings are in agreement with other studies [8] and [9]. Low serum vitamin A levels are associated with increased mortality, more rapid disease progression and an increased maternalfetal transmission. Zinc is an important micronutrient in immune function, and therefore Zinc deficiency is of great importance in HIV infection. The study findings indicated that there was a decrease in proportion of people with low BMI with increasing level of education. This is consistent with a study [4]. There was no significant association between CD4 count and nutritional status and this was in line with a study [5]. Despite majority of the study population being food diverse, more than half were mildly food insecure. The household food security condition based on Household Food Insecurity Access yielded comparable results to those of a study [11]. In the same study Households had limited variety of foods based on the Household Dietary Diversity Score as opposed to the current study outcomes where $80 \%$ of the study population consumed diversified diets. These differences could be attributed to seasonality, geographical differences, study population size, study design and political stability.

\section{Conclusion and Recommendation}

Prevalence of under nutrition in the study population shows that $31.6 \%$ of subjects had inadequate Folate and Zinc intakes. Folate intake was a significant predictor of undernutrition. We recommend that patient health education on the need to consume foods rich in Folate and Zinc should be intensified in all the ambulatory clinics.

\section{Acknowledgements}

We wish to thank the staff of the nutrition, nursing and records departments at the various modules of the AMPATH centre for their relentless support during data collection. Much appreciation also goes to the HIV infected patients who took part in this study.

\section{References}

[1] Benhura M. A. and Chitsiku I (1988): Food consumption patterns of the people in the Mutambara District of Zimbabwe. Proceedings of the Third Africa Food and Nutrition Congres.

[2] FANTA. AED: HIV/ AIDS (2004) Washington D. C: A guide for Nutrition, care and support. Washington D. C.

[3] FANTA Project (2007): New Approaches for Measuring Household Food Insecurity and Poverty: the Household Food Insecurity Access Scale (V. 3).

[4] FANTA Project (2006): Household Dietary Diversity Score (HDDS) for Measurement of Household Food Access: Indicator Guide (V. 2). 
[5] Gorbach SL (1993): Interactions between nutrition and infection with human immunodeficiency virus.

[6] Joint United Nations Program on HIV/AIDS (2009): AIDS Epidemic Update.

[7] Kenya National Bureau of Statistics (KNBS) and ICF macro (2010): Kenya Demographic and Health Survey (2008-2009).

[8] Kotler DP (1989): Malnutrition in HIV infection and AIDS. AIDS 3 (Suppl 1): S175-S180.

[9] Mary-John L et al (2005): Body Composition in adults infected with HIV. Khon Kaen, Thailand.
[10] Mutimura E et al (2010): Effect of HIV infection on Body Composition and Fat Distribution in Rwandan women.

[11] National Aids and STI Control Program (NASCOP) (2005): Aids in Kenya. Trends, Interventions and Impact. NASCOPNairobi, Kenya.

[12] National AIDS and STI Control Programme (NASCOP), Kenya. Kenya AIDS Indicator Survey 2012: Final Report. Nairobi, NASCOP. (June 2014).

[13] Olelakan A. (2008): Prevalence and pattern of HIV- related Malnutrition among women in Sub- Saharan Africa. 